\section{NOVA TELLVS}

\section{kyth}

Nova Tellus

ISSN: 0185-3058

novatelu@servidor.unam.mx

Centro de Estudios Clásicos

México

García Pérez, David

La muerte: su significación y su representación en la poesía griega

Nova Tellus, vol. 27, núm. 2, 2009, pp. 91-106

Centro de Estudios Clásicos

Distrito Federal, México

Disponible en: http://www.redalyc.org/articulo.oa?id=59115485003

- Cómo citar el artículo

- Número completo

- Más información del artículo

- Página de la revista en redalyc.org

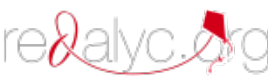

Sistema de Información Científica

Red de Revistas Científicas de América Latina, el Caribe, España y Portugal

Proyecto académico sin fines de lucro, desarrollado bajo la iniciativa de acceso abierto 


\title{
La muerte: su significación y su representación en la poesía griega
}

\author{
David GARCÍA PÉREZ \\ Universidad Nacional Autónoma de México \\ prometeo9@att.net.mx
}

RESUMEN: Este trabajo tiene como objetivo trazar una lectura y un comentario críticos de las ideas centrales de Jean-Pierre Vernant en torno al concepto de la muerte. Para tal propuesta, el sentido del mito y la religión en la antigua Grecia son ejes medulares en aras de definir la significación de la muerte en la poesía épica, la lírica y la dramática de los antiguos griegos. Una vez dilucidado este punto, se examina la representación de la muerte en la tragedia en tanto mímesis y rito, guiados por el sistema antropológico y filológico de Vernant.

$$
* * *
$$

ABSTRACT: The aim of this study is to put forward a reading and a critical commentary on the main ideas developed by Jean-Pierre Vernant about the conception of death in ancient Greece. According to the proposal of the author, elucidating the core meaning of myth and religion among the Greeks is the key path to define the significance of death in their epic, lyric and dramatic poetry. Once achieved this goal, the way death is represented on stage in the tragic works as a mimesis and a rite is examined under the guidance of Vernant's anthropological and philological system.

PALABRAS ClAVE: Jean-Pierre Vernant, mímesis, muerte, poesía griega antigua, ritual.

KEYWORDS: ancient greek poetry, death, Jean-Pierre Vernant, mímesis, ritual.

RECEPCIÓN: 5 de junio de 2009.

ACEPTACIÓN: 23 de octubre de 2009. 


\title{
La muerte: su significación y su representación en la poesía griega*
}

\author{
David GARCÍA PÉREZ
}

Para el griego antiguo, ¿qué era la muerte?, ¿a dónde iba a parar el ser humano una vez muerto?, ¿al infierno?, ¿hay otro espacio posible donde yacer fuera de éste? ¿cómo se puede llegar a él? Y una vez estando ahí, ¿es posible volver al mundo de los vivos, a la tierra?, ¿y para qué volver? Tal vez el hombre se queda en el mismo lugar, es decir, en el origen de todo: la tierra. Sin duda, la idea de la muerte ha sido una tribulación en el destino de la humanidad, que ha tratado de ser explicada de diverso modo a cada momento. Los antiguos griegos no fueron la excepción, pues el significado y la representación de la muerte fueron mecanismos dinámicos, tal como se distinguió su cultura por la dialéctica constante.

La creación literaria se ha ocupado de esta cuestión desde el momento en el que aparece el primer titubeo sobre las formas de la literatura. La muerte es de los primeros mitos que la literatura explora como respuesta a la curiosidad y a la angustia del hombre por la esencia y el fin de la vida. Pero los textos literarios, por su propia naturaleza, ofrecen una ficción de la muerte, no una respuesta. En efecto, la literatura alimenta aún más el halo incomprensible de la muerte. Al no poder revelarse su misterio, aquélla queda como un mito inmarcesible. De esta manera, mito y literatura llegan a ser sinónimos.

\footnotetext{
* Este trabajo fue presentado originalmente como conferencia en el Colloque International Relire Jean-Pierre Vernant y es parte del proyecto de investigación “Teatro clásico grecolatino y su tradición en Occidente" PAPIIT IN-403308.
} 
Cada época, cada autor y cada cultura exponen de manera particular la cuestión de la muerte, y a partir de su propuesta nace el signo bajo el que se le puede reconocer: sus características, sus elementos de culto y de rito, es decir, que a través de este proceso el mito de la muerte se renueva en cada creación y en cada lectura. El símbolo contiene una multiplicidad de significados, y cada uno de ellos encuentra su justificación en la medida en que se acopla a la realidad que trata de definir. Sin embargo, no se trata de enunciar el significado del símbolo, sino de analizar algunos de los múltiples rostros que tiene. En el plano del signo, nada más abierto temáticamente que los mitos que la literatura ha creado sobre la muerte, pues los poetas enriquecen con la ficción literaria la imagen de ella, y de ella absorben las manifestaciones populares como material básico que incorporan su configuración. Pues bien, veamos algunos ejemplos de la literatura griega para pergeñar una idea de thánatos.

La muerte de Patroclo y la de Héctor, en la Ilíada, caracterizan el sentido ritual del combate y el modo en que concluye la vida del héroe. Llevado prácticamente de la mano por el destino hasta el punto final de su existencia, el héroe construye su propio monumento que, en un momento específico, es derruido por la presencia de la muerte. El héroe llega a las puertas de Hades una vez que ha concluido su aristía. Héctor muere cuando ha cumplido con sus obligaciones como guerrero en relación con su comunidad y como pariente con su familia; cubiertas las premisas que lo definen como héroe, la muerte se le presenta en la flor de su juventud, cuando "todo le va bien al joven / incluso muerto por intervención de Ares [...] / ya muerto, todo lo que de él se muestra es bello". ${ }^{1}$ Patroclo demuestra que, no obstante que va disfrazado de Aquiles, tiene tal arrojo que detiene el avance de los troyanos, cobrándose la vida de muchos enemigos. De igual manera, la destre-

\footnotetext{
${ }^{1}$ Hom., Il., XXII, 71-73.
} 
za guerrera de Héctor da victorias importantes a los troyanos, él es el escudo de su patria y, sin paradoja, su muerte a manos de Aquiles es la culminación de su heroísmo.

Cuando Patroclo muere, lleva puestas las armaduras de Aquiles. No es él en verdad quien lucha y a quien la muerte en forma de Héctor persigue. Pero el destino está marcado y debe fenecer. Patroclo fallece bajo el influjo de una ilusión. Cuando Héctor marcha para encontrarse frente a frente con Aquiles, tiene la certeza de que es su destino el que lo conduce a tal encuentro, al grado de rechazar las palabras de Príamo, su padre, de que se ponga a salvo tras las puertas de Troya. Héctor sí es él mismo, a diferencia de Patroclo, pero la ilusión también lo hace su presa y cree poder vencer a Aquiles, para sólo darse cuenta luego de que los dioses han decidido ya su suerte final. El poeta usa la misma fórmula para indicar el momento preciso en que la muerte cae sobre los dos héroes:

Luego de que así habló, el fin de la muerte lo arropó y su alma, habiendo volado de sus miembros, llegó al Hades, su destino lamentando, pues abandonaba su varonil juventud. ${ }^{2}$

Al estar muriendo, Patroclo predice la muerte de su ulterior homicida, pues afirma que "la muerte y el destino poderoso"

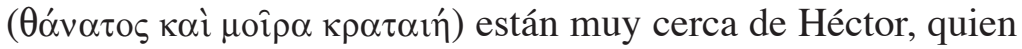
habrá de morir a manos de Aquiles. ${ }^{3}$ De similar forma, Héctor, muriendo, le dice a Aquiles, que llegará el día en que Paris y Apolo lo liquiden ante las puertas Esceas. ${ }^{4}$ Como el poeta señala, estos personajes llegan a la muerte en la plenitud de su hombría y de su juventud, de modo que tal característica resulta imprescindible para que sean considerados como héroes.

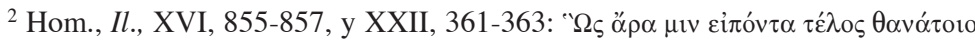

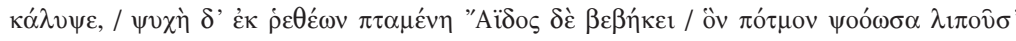

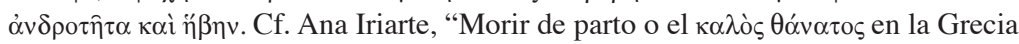
arcaica y clásica", pp. 16-18.

${ }^{3}$ Hom., Il., XVI, 844-854.

${ }^{4}$ Hom., Il., XXII, 356-360.
} 
El caso de Aquiles es el ejemplo diáfano de tal circunstancia, pues el destino le propone tener una vida larga, con esposa e hijos, y llegar a la muerte en su lecho, pero sin cultivar ni cosechar la fama que acompaña al héroe; o bien, elegir lo que "les Grecs appelent la vie brève et la belle mort, kalos thanatos. Il n'y a pas de belle mort s'il n'y a pas de vie brève". 5

Tales similitudes, que no son las únicas, si bien obedecen al estilo homérico caracterizado por la repetición de fórmulas y de imágenes en acción, indican, además, una pintura que el poeta recrea constantemente en torno al sentido de la muerte. Tres cosas llaman la atención: en primer término, el destino es la muerte que se hace presente a través de la dualidad formada por un ser humano y uno divino. La sucesión es clara: del destino se desprende la voluntad de los dioses que hace responsable a un sujeto para liquidar a otro. Entonces, en segundo lugar, el individuo que funge como instrumento del destino es el otro que, como imagen, reproduce la muerte, pues a la vez que acaba con su enemigo, oye en sus palabras y ve en el aspecto del que muere cómo es que su vida concluirá también. En tercer lugar y si lo anterior es así, se abre un espacio en el que el homicida y el muerto se reconocen en el tránsito que oscila entre la vida y la muerte. Hay, pues, un compás de espera en el que se manifiesta el rostro del otro que es la representación de la muerte, la alteridad absoluta. En un comentario en torno al sentido de la muerte en la poesía homérica, Pseudo-Longino afirma que el poeta

representa los cardenales de los dioses, sus inquinas, sus venganzas, lágrimas, confinamientos, todas sus emociones, hace lo imposible por transformar a los guerreros que luchan en Troya en

\footnotetext{
${ }^{5}$ Jean-Pierre Vernant, La mort hérö̈que chez les grecs, p. 13. Sobre la muerte de Héctor bajo la idea de kalos thanatos, cfr. "La belle mort et le cadavre outragé", en Gherardo Gnoli et Jean-Pierre Vernant, La mort, les morts dans les sociétés anciennes, pp. 45-70. Cf. Ana Iriarte, op. cit., pp. 15-16.
} 
dioses y los dioses en hombres. Nosotros, en la desgracia, hallamos en la muerte un puerto para nuestros males. ${ }^{6}$

Los dioses lucharían por un tiempo infinito, el esfuerzo heroico del hombre termina por agotarlo y sólo en la muerte encuentra reposo. Ante la experiencia de la muerte, el sujeto vivo puede experimentar el sentido de la existencia mirándose en el que muere. En efecto, el individuo se comprende a partir del otro, tal como se patentiza si colocamos en secuencia las palabras que en el momento justo de fenecer se dirigen el ejecutor y la víctima: Héctor y Patroclo, Aquiles y Héctor. Y ese otro revela diversas maneras de ser o de presentarse, una de las cuales es la muerte, el Otro absoluto (l'Autre absolu), como definió Vernant. ${ }^{7}$ Quizá la principal operación de la alteridad consiste en aprehender lo diverso desde la visión del uno. La constante definición de ese uno concluye con la muerte, por ello la necesidad de acercarse a ésta desde diferentes acciones, visiones, contextos. La constatación del otro se advierte en la escena de la Odisea cuando el Laertíada se encuentra con Aquiles en el inframundo. Odiseo cree que Aquiles es feliz por estar muerto y por gozar de una fama semejante a la de los dioses y por imperar entre los muertos. Sin embargo, el Pelida dice que él preferiría estar vivo que reinando entre las sombras. La muerte heroica edificó su fama perenne, su kalòs kaì agathós, pero frente a la vacía inmensidad del Hades, Aquiles preferiría el goce de la vida efímera:

No pretendas, Ulises preclaro, buscarme consuelos de la muerte, que yo más querría ser siervo en el campo de cualquier labrador sin caudal y de corta despensa que reinar sobre los muertos que allá fenecieron. ${ }^{8}$

\footnotetext{
${ }^{6}$ [Longinus], Subl., IX 7.

${ }^{7}$ Jean-Pierre Vernant, La mort héroïque chez les grecs, p. 28.

${ }^{8}$ Hom., Od., XI, 488-491.
} 
El hombre es efímero. Bien lo sabía Homero. Sin embargo, la sociedad que retrató, basaba el reconocimiento social en la construcción del héroe, quien demostraba que era digno de sí mismo, de su familia y de su comunidad a través de su habilidad en el ágora y en el campo de batalla. ${ }^{9}$ Este último era el espacio más propicio para alcanzar el signo del héroe, no obstante que en ello se fuera la vida: "Les Grecs y répondent en liaison avec cette culture aristocratique de l'honneur héroïque, par cette idée de la mort héroïque. Il va donc y avoir indépendamment de ce que je viens de vous dire une dimension métaphysique". ${ }^{10}$

Por otra parte, la queja de Aquiles bien puede considerarse como un puente hacia el ámbito de la poesía lírica y recalca la diferencia respecto de Odiseo, pues éste héroe "est l'homme du retour chez lui, de la longe vie avec sa femme, de la fidélité à lui-même, à Ithaque, à Pénélope, à sa propre vie". ${ }^{11} \mathrm{La}$ individualidad alcanza matices que rebasan el aliento épico. La vida se aprecia en la medida en que se sabe efímera. La reflexión sobre el escaso momento en que se vive da lugar a la queja o a la celebración del poeta lírico. Siendo esto así, el sujeto de la lírica, en general, mira a la vida de frente para intensificar cada momento. La muerte se deja para después, una vez que se sabe inevitable y que no necesariamente, a pesar de que sea heroica, acarrea la fama, que también se comprende ya fugaz:

Nadie, de honor ni fama, una vez muerto, goza entre sus convecinos: en vida preferimos

\footnotetext{
${ }^{9}$ En Entre mythe et politique, p. 502, Vernant apuntó: "Dans une société de face-à-face où, pour se faire reconnaître il faut l'emporter sur ses rivaux dans une incessante compétition pour la gloire, chacun est placé sous le regard d'autrui, chacun existe par ce regard. On est ce que les autres voient de soi. L'identité d'un individu coïncide avec son évaluation sociale: depuis la dérision jusq'à la louange, du mépris à l'admiration".

${ }^{10}$ La mort hérö̈que chez les grecs, p. 21.

${ }^{11}$ Ibid., p. 30.
} 
buscar de los vivientes la simpatía; el muerto

lo peor de todo, siempre y en todas partes, sufre. ${ }^{12}$

Vernant explica que ante la vacuidad que implica la muerte, signo del fin de la efímera condición humana, en la poesía homérica se percibe "que la mort heroïque a été ainsi idéalisée comme solution vertigineuse et incroyable à une condition humaine marquée par la mortalité. Et par conséquent, le héros qui choisit la mort héroïque, accueille aussi l'idée qu'il existe des puissances qui symbolisent la mort". ${ }^{13}$ En cambio, el poeta lírico, en general, encuentra, en el goce de la vida, la manera de conjurar la pesadez de la muerte y de los males que conducen a ella. La alternancia de los males y de los bienes es la imagen propia de la existencia, hasta que se hace presente la desgracia insoslayable, la muerte, tal como Anacreonte lo expresa al hablar de la vejez como la antesala del Hades, terrible y doloroso, pues quien a él baja ya nunca sube. ${ }^{14}$ Se trata de un viaje sin retorno.

Sin embargo, hay otro tipo de viaje que se halla engarzado a la idea de la alteridad y a la de muerte, pues los personajes que realizan el periplo emigran a un mundo extraño, incivilizado, donde el peligro de morir es constante. Así, al describir ese otro mundo y al nombrarlo, los forasteros se constituyen también como traductores de los signos culturales.

En cierto modo, el viaje de Odiseo es una prueba fatal, pues el librarla equivale a seguir con vida. De todo el ejército que acompañaba al Laertíada en el periplo de Troya a Ítaca, sólo él sobrevivió. Cada aventura que este héroe experimentó en el ámbito de lo no-griego ponía en juego su sabiduría. Y ésta era una representación de la civilización, de lo cultivado, según las normas de lo griego. Si, de acuerdo con Vernant, Artemisa

\footnotetext{
${ }^{12}$ Arq. frag. 64 D. Traducción de J. Ferraté.

${ }^{13}$ La mort héroïque chez les grecs, p. 28.

${ }^{14}$ Anac. frag. $40 \mathrm{P}$.
} 
"fait en sort qu' entre le sauvage et le civilisé les frontières soient en quelque façon perméables, puisque la chasse nous fait passer de l'un à l'autre", ${ }^{15}$ Odiseo deviene, correlativamente, en nexo entre los mundos confrontados, entre la civilización y la barbarie; de ésta, su punto más alejado es el Hades. En efecto, hay un tránsito de la vida a la muerte que atraviesa por el espacio de lo no civilizado. Separarse del núcleo de lo cultivado es comparable a reducirse a la animalidad, y de ésta el paso a la muerte es breve. El espacio que va de la frontera de Ísmaro a las playas de Esqueria es un ámbito en donde la alteridad absoluta adquiere rasgos sígnicos propios de una traducción cultural, ${ }^{16}$ porque el relato de las aventuras de Odiseo implica una exégesis de los rasgos culturales del mundo bárbaro e incivilizado en el marco de lo que se define culturalmente como lo griego.

Un ejemplo notable en que el viaje re-significa la cultura a través del otro se halla en el periplo de Ío, descrito por el autor de la tragedia Prometeo encadenado. Es posible trazar una comparación entre Odiseo e Ío en cuanto a su inmersión en el espacio del otro a través de los avatares del viaje. Los sucesos que comportan el periplo están sujetos, por una parte, a la comprensión cultural entre el observador del que parte el relato y que crea un imaginario a partir de la confrontación del uno frente al otro; por otro lado, a la ausencia de una secuencia lineal del relato, pues el tiempo del mito es circular y por ello se amplían las posibilidades de la narración. ${ }^{17}$ En su itinerario, la doncella llega a tener tantos encuentros con lo otro como sean posibles, castigada como está a andar errante por muchos luga-

\footnotetext{
${ }^{15}$ La mort dans les yeux, p. 18.

${ }^{16}$ Según Peter Torov, La traduzione totale, p. 25, la traducción cultural es "un processo in cui, benché a ciascun livello della lingua dell' originale venga sostituito del materiale testuale nella lingua della traduzione, ciò non significa necessariamente che a tutti i livelli tale sostituzione avvenga mediante "equivalenti' ".

${ }^{17}$ El mito, sobre todo aquel que se halla en el medio de la oralidad, funciona bajo las reglas del tiempo circular, es decir, un tiempo sin tiempo.
} 
res incesantemente, ${ }^{18}$ antes y después del hic et nunc dispuesto según el relato de Prometeo encadenado. Así, el viaje supone la definición de lo que es propio del personaje en cuestión a través de la mirada que sobre el otro se construye. ${ }^{19}$

Hay una frontera entre la vida y la muerte que encuentra diversas representaciones no sólo en el ritual que significa traspasar el umbral de un estado al otro, sino que se manifiesta de diverso modo en las actividades y en las formas cotidianas de la cultura. Vernant hace notar que Artemisa es una deidad que marca esa distancia entre lo civilizado y lo agreste e indica cómo los espacios tienen vasos comunicantes, "des zones limitrophes, des frontières où l'autre se manifeste dans le contact qu'on entretient régulièrement avec lui, sauvage et cultivé se côtoyant, pour s'opposer certes, mais pour s'interpénétrer tout autant". ${ }^{20}$ El paso de un espacio a otro puede significar la muerte del personaje que lleva a cabo tal acción. Por ello hay modos de ir al inframundo y de volver de él con vida. Odiseo, Sísifo y Psique son ejemplos literarios, alimentados por un imaginario religioso antiquísimo y popular de tal situación.

El viaje de Ío sitúa la temporalidad fuera de cualquier referente inmediato, porque lo dicho por Prometeo, como profecía, se refiere a la descripción de un mundo bárbaro y fantástico que escapa a la realidad presente del mundo ateniense de la democracia, pero que estaría latente ahí, a un lado, dividido por unas fronteras sutiles, de Asia y de África. ${ }^{21}$

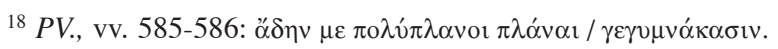

${ }^{19}$ Carlos García Gual, "Viajes griegos. Viajes reales y fantásticos”, p. 22: "Viajar lejos era enfrentarse a lo otro y a los otros, tratar con gentes bárbaras que no hablaban en griego y tenían costumbres peculiares; y en esas brumosas y quiméricas lejanías podía uno llegar a toparse con seres no humanos del todo, sino con criaturas bestiales, hombres de cabeza de perro o descabezados con un ojo en el pecho, porque en los extremos del mundo pululaban, según creencia general, los monstruos y las maravillas".

${ }^{20}$ La mort dans les yeux, p. 17.

${ }^{21}$ Cf. $P V$., vv. $700-740,786$ ss.
} 
Si bien el espacio civilizado y el agreste refieren una concepción cosmológica y cultural del pueblo, también es un modo de hacer ver los peligros de lo fronterizo, del acecho de la muerte en la línea que divide a un mundo del otro. La geografía que transita Ío no se corresponde estrictamente hablando con ningún modelo social o ideológico conocido directamente por los atenienses, pues la doncella transformada en vaca, es lanzada al mundo no griego, que es irracional y que no conoce las formas civilizadas de convivencia, pero que, al mismo tiempo, es producto del imaginario mitológico de ese pueblo. Lo paradójico es que Zeus tampoco reconoce tales formas, según se colige de la versión esquilea, y ésa es la controversia que tangencialmente plantea Prometeo, pues él afirma que el Cronida ejerce la justicia de modo caprichoso, a pesar de que, con el correr del tiempo, las cosas habrán de encontrar su equilibrio, al menos en la disputa que estos dos dioses sostienen. ${ }^{22}$ Entonces, la única diferencia entre el Cronida y cualquiera de los personajes que habitan el mundo bárbaro y fantástico es el de la investidura. Si esto es así, en el viaje de Ío, a través de los pueblos y seres que conoce, conceptos como tiranía y democracia no tienen sentido alguno, pues una acción como ésta "excluye el tiempo profano y participa del tiempo mítico". ${ }^{23}$

Además, hay una sutil sugerencia que el dramaturgo siembra en el público: la comparación entre una sociedad griega estructuralmente organizada bajo la democracia, con otra que no presenta este rasgo. El gobierno de Zeus se encamina hacia ese mundo ya rebasado en el hic et nunc en el que Prometeo dialoga con Ío, lo cual denota una barrera entre las intenciones destructoras de aquél y la redención del Titán.

Odiseo encontró en su viaje un mundo desconocido y poblado de seres que, para su imaginario y, por lo tanto, para el del auditorio inmediato de tales aventuras, fueron percibidos como

\footnotetext{
${ }^{22}$ Cf. $P V$., vv. 186-192.

${ }^{23}$ Mircea Eliade, Aspectos del mito, p. 42. Cf. Rush Rehm, The Play of Space, p. 157.
} 
mitológicos. De igual modo, Ío fue lanzada a errar por un mundo en el que la humanidad en términos estrictos era desconocida $\mathrm{y}$, en varios casos, ella, que era un esperpento, se topó con seres monstruosos que se asimilan con el rostro de la muerte. Quizá por sus características, que oscilan entre lo vacuno y lo humano, Ío fue desterrada al universo que le correspondía de acuerdo con su apariencia. Se trataba de un mundo en donde los sustentos de la naturaleza no estaban domesticados, era un espejo de los mismos seres que allí vivían. La metamorfosis de Ío no sólo era una transformación física, sino que también colocaba al personaje en el mundo del mito fantástico; por esta razón, la doncella se convirtió, además, en el puente con otra realidad que confrontaba y definía lo griego.

Ahora bien, el viaje de Ío y el trance que éste significa, adquiere su acepción por la metamorfosis de la doncella que, a su vez, es simbolizada por la máscara que debió portar dicho personaje. A través de la máscara el público comprendía la definición trágica del personaje, pero al mismo tiempo enmascara la enunciación de lo otro. $^{24}$

Cierto tipo de máscara refiere un nexo con la muerte, cuando no se representa a ésta de modo directo. Vernant ha hecho notar que la representación de Gorgo denota la ambigüedad entre la profilaxis y la muerte. El choque entre la mirada de Gorgo y del hombre puede traer nefastas consecuencias para éste, porque dicho encuentro conduciría al sujeto a los terrenos del Hades. Los ojos de la Gorgona, de otro modo, son una vía hacia la muerte. La Gorgona es la única mortal del grupo de las Greas y, no obstante que muere, su cabeza sigue viva y resulta un eficaz instrumento de guerra. ${ }^{25}$

\footnotetext{
${ }^{24}$ Véase el comentario de Jean-Pierre Vernant en torno al significado de la máscara en las Bacantes de Eurípides: "El Dioniso enmascarado de las Bacantes de Eurípides", en Jean-Pierre Vernant y Pierre Vidal-Naquet, Mito y tragedia en la antigua Grecia, vol. II, pp. 223-252.

${ }^{25}$ Cf. Jean-Pierre Vernant, La mort dans les yeux, pp. 39-54; "Figuras de la máscara en la antigua Grecia", en Jean-Pierre Vernant y Pierre Vidal-Naquet, Mito y tragedia en la antigua Grecia, vol. II, pp. 34-35.
} 
Ahora bien, la máscara trágica, si bien pudo tener un origen religioso, en la representación teatral adquirió otros matices, tan profundos que es posible advertir a través de ella una comprensión de la existencia humana. La antigua máscara de los rituales religiosos obedecía, en cierto modo, a la mímesis que el sujeto ejecutaba para explicarse: ya no era él, sino otro quien pasaba a formar parte de la naturaleza, quizá porque se advertía, en un momento dado, ajeno ya de ella, y la máscara, como parte de un ritual, indicaba esa pertenencia al cosmos. Y, al mismo tiempo, era signo de la separación. Sin embargo, en la tragedia, la máscara no hacía salir al individuo para que formara parte del todo, sino que lo individualizaba y, al hacerlo, contenía la dialéctica del ser y del deber. Así, la máscara trágica oculta más de lo que en sí refleja. Los gestos que pudiera expresar, de algún modo estáticos en la ejecución de una escena, no eran suficientes para denotar el pathos que implica definir el ser y la pesadumbre que resultaba el cumplimiento del deber. Era, entonces, el artilugio de la palabra el instrumento que revelaba la congoja de los personajes y la tensión de sus acciones. ${ }^{26}$ La máscara debía adquirir los más finos matices del discurso de la tragedia. Como un modo de ocultamiento, la máscara sepulta el ser del individuo, como un medio de proyección al exterior el deber se impone.

La máscara de la Gorgona manifiesta notablemente la significación de lo trágico, pues a través de la alegoría que los dramaturgos dibujaban con palabras para la tragedia, es como se delimita una representación de este concepto: Edipo tirano debió aparecer en la entrada de la tragedia de Sófocles con una máscara que reflejara la potestad de rey-sabio, de aquel que detenta el poder de modo absoluto y, al final de dicha obra,

\footnotetext{
${ }^{26} \mathrm{Si}$ bien el espectáculo teatral era un todo que conjuntaba los distintos códigos dramáticos - escenografía, coreografía, texto escénico, etcétera - era tan sólo la palabra lo que guiaba y sostenía la ejecución del drama. Aristóteles, Poet., 50b 1721 , indicaba ya que los sentimientos de lo trágico sólo podían tener causa y efecto a partir del uso de la palabra.
} 
lo hallaríamos con otra máscara, con las cuencas de los ojos vacías y, quizá, con sangre corriendo por sus mejillas. Es un rostro gorgónico, cuya vaciedad en la mirada es como la de la Grea mortal, el camino hacia el más allá. Así, la ceguera de Edipo es metáfora de la muerte en vida. En otro caso, Eurípides perfila el rostro colérico de Heracles que ya no es más su faz, sino la de un ser monstruoso: "Heracles ya no era el mismo: alterado en el movimiento de sus ojos y dejando ver en ellos las raíces enrojecidas, arrojaba espuma sobre su barba bien poblada. Y dijo de pronto con risa enloquecida". Los sirvientes se preguntarán, luego, si su amo está loco. En efecto, lo está. La locura, Lyssa, transforma el rostro del héroe hasta hacerlo desconocido. ${ }^{27}$ La locura es la antesala de la perdición. Y, como se ha demostrado, la locura proviene de dios. ${ }^{28}$

Hemos anotado, en general, tres ideas sobre la muerte que corresponden a los distintos géneros de la poesía: la muerte heroica, propia de la poesía homérica, que, de acuerdo con Vernant "procure non seulement un honneur incomparable mais réalise le paradoxe d'un créature humaine, mortelle éphémère, vouée au cycle - le passage par des stades jusqu'à la mort lamentable - qui caractérise l'homme et qui l'oppose aux dieux". ${ }^{29}$ Por otra parte, la oposición entre vida y muerte que los líricos resaltaron a fin de comprender el sentido efímero de la existencia y la vanidad de la fama heroica. Y, por último, la representación de la muerte en el periplo y la máscara, que toca, en parte, a la poesía trágica.

Como se observa, las preguntas que al principio planteábamos, tienen respuestas que obedecen al espacio y al tiempo que el poeta captura en sus versos: la muerte heroica, el hombre efímero y la máscara terrible del otro absoluto son signo y representaciones de la muerte, cada una de ellas en la cons-

\footnotetext{
${ }^{27}$ Eur., Her., vv. 931 y ss.

${ }^{28}$ Ruth Padel, A quien los dioses destruyen, passim.

${ }^{29}$ La mort héroïque, pp. 19-20.
} 
tante oposición del nacer y del morir, pues, como reflexiona Vernant, ${ }^{30}$ ella siempre se encuentra ahí, agazapada en la vida misma, bajo los rostros de Hypnos, Pónos, Gêras o Limós, esperando dar el zarpazo final.

\section{BIBLIOGRAFÍA}

Eliade, Mircea, Aspectos del mito, Barcelona, Paidós, 2000.

GARcía GuAL, Carlos, "Viajes griegos. Viajes reales y fantásticos", en Joaquín Rubio Tovar et al. (eds.), Viajes y visiones del mundo, Málaga, Ediciones Clásicas, 2008.

GNOLI, Gherardo et Jean-Pierre Vernant, La mort, les morts dans les sociétés anciennes, Paris, Éditions de la Maison des Sciences de l'Homme -Cambridge University Press, 1982.

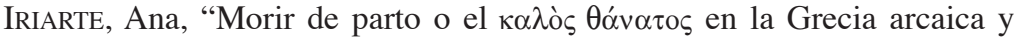
clásica", en Francisco Marco Simón et al. (eds.), Formae mortis: el tránsito de la vida a la muerte en las sociedades antiguas, Barcelona, Publicacions i edicions de la Universitat de Barcelona, 2009, pp. 13-24.

PADEL, Ruth, A quien los dioses destruyen. Elementos de la locura griega y trágica, México, Sexto Piso, 2005.

ReHM, Rush, The Play of Space. Spatial Transformation in Greek Tragedy, Princeton, Princeton University Press, 2002.

Torov, Peter, La traduzione totale, Ferrara, Guaraldi Logos, 2001.

Vernant, Jean-Pierre, Entre mythe et politique, Paris, Éditions du Seuil, 1996.

—, La mort dans les yeux. Figures de l'autre en Grèce ancienne. Artémis, Gorgô, Paris, Hachette, 1998.

-, La mort hérö̈que chez les Grecs, Nantes, Éditions Pleins Feux, 2001.

-, El individuo, la muerte y el amor en la antigua Grecia, Barcelona Paidós, 2001.

- , et Pierre Vidal-NaQuet, La Grèce ancienne. 2. L'espace et les temps, Paris, Éditions du Seuil, 1991.

-, y Pierre Vidal-NaQuet, Mito y tragedia en la antigua Grecia, vols. I y II, Barcelona, Paidós, 2002.

\footnotetext{
${ }^{30}$ El individuo, la muerte y el amor en la antigua Grecia, pp. 20-21.
} 